\title{
Assessment of Biosorption Potential of Poplar Sawdust for Removal of Dyes from Wastewater under Single and Binary System
}

\author{
Vartika Gupta, Arunima Nayak, Brij Bhushan, Vijay Kumar
}

\begin{abstract}
In the present study, the performance of raw sawdust (RSD) as a biosorbent was assessed for the removal of model dyes (MB-Methylene blue and CR-Congo red) in single as well as binary systems under various wastewater conditions. Biosorption studies in single system under simulated wastewater conditions showed highest uptake of MB and CR taking place at $\mathrm{pH} 6$ and 2, respectively. $\mathrm{pH}$ and FTIR studies revealed the binding to be electrostatic in nature, while a inter-particle diffusion mechanism was found to be operative. Irrespective of the nature of the dye, equilibrium was found to be achieved within 60 mins. Biosorption studies carried out in binary systems under similar experimental conditions in simulated wastewater showed no significant difference in the removal efficiency. This could be attributed to the fact that there is no competitive relationship between the cationic (MB) and anionic (CR) dyes when present simultaneously in the wastewater. On the other hand, the results as obtained under real wastewater binary system reveal lower removal capacity for the removal of the dyes which could be due to competitive adsorption of organic pollutants as verified by a 50 $\%$ reduction in COD in the real wastewater. Irrespective of the wastewater conditions, isotherm studies showed that at lower adsorbate concentrations, the Langmuir model was operative while the Freundlich model showed higher correlation at higher adsorbate concentrations. Experimental results thus verify the usefulness of RSD as an economic, cost effective and potential biosorbent for the removal of dyes from diverse wastewater conditions
\end{abstract}

Keywords: sawdust; biosorbent; binary dye sorption; real wastewater; isotherm model; kinetic

\section{INTRODUCTION}

Rapid industrialization has resulted in the generation of polluted water bodies which has become a serious problem to human beings. Such wastewaters may contain undesirable color, degradable and non-degradable organic pollutants as well as toxic inorganic metal ions [1].Amongst them, dyes are considered as important class of organic pollutants because the dyes bearing wastewater have strong color even at very trace level, which is environmentally and aesthetically objectionable. Because of the chemical stability and low bio-degradable nature of dyes, various conventional treatment techniques are not efficacious for their sequestration from aqueous solution [2]. In recent years, adsorption technology has been documented as a versatile technique for wastewater treatment owing to its ease of process, high efficiency andlow maintenance cost [3].

Revised Manuscript Received on September 25, 2019.

Vartika Gupta, Department of Chemistry, Graphic Era University, Dehradun, India.

Arunima Nayak, Department of Chemistry, Graphic Era University, Dehradun, India.

Brij Bhushan, Department of Chemistry, Graphic Era University, Dehradun, India

Vijay Kumar, Department of Physics, Graphic Era Hill University, Dehradun, India
Lignocellulosic based biosorbent, because of their widespread availability as well as favorable surface functionality of cellulose, lignin and hemicellulose have demonstrated good adsorption potential for diverse pollutants $[4,5]$. From the last decade, a large variety of lignocellulosic wastes (fruit peels, sugar-cane bagasse, poplar leaves, coconut fibre, peanut hulls, hazelnut shell and sawdust etc.) have been investigated as potential biosorbent for wastewater treatment [6-12]. In this context, sawdust a lignocellulosic waste product of the timber industry has also been extensively studied upon and has successfully demonstrated good sorption properties for model metal ions $[13,14]$, dyes [15, 16], pesticides [17] etc from simulated wastewaters. Literature reveals that studies have extensively been conducted on accessing the biosorption potential of sawdust from various tree species like walnut, pine, neem, cedar, oak, rattan, beech, bamboo, meranti, coconut etc. [1827]. A summary of such studies is that irrespective of the various tree species, the rich surface chemistry of lignin, cellulose and hemicellulose has a major effect on good biosorption properties of sawdust. The findings further reveal that such studies have been conducted in simulated wastewater conditions. But it is a well-acknowledged fact that industrial waste effluents have diverse chemistry with the presence of both organic and inorganic moieties. Limited studies have demonstrated the usefulness of sawdust under such real industrial wastewater conditions.

The focus of the present study was hence to assess the potential of sawdust as a biosorbent under batch mode in both simulated and real wastewater conditions. Two model dyes- anionic (CR-Congo red) and cationic (MB-Methylene Blue) were selected for the study; the aim of which was to conduct an in depth study on the nature of the binding mechanism. While studies conducted in simulated conditions were used to investigate the various optimum conditions and the nature of the binding process, the same conducted in real waste water conditions was used to verify the removal capacity of the dyes by the biosorbent. Isotherm studies were also made to explore the nature of the model dyes during the adsorption phenomenon.

\section{MATERIAL AND METHODS}

\subsection{Preparation of biosorbent}

Sawdust was collected from a local timber industry at Saharanpur (U.P.), India. Initially, Sawdust was continuously cleansed with water to remove any dust or impurities adhere on its surface,

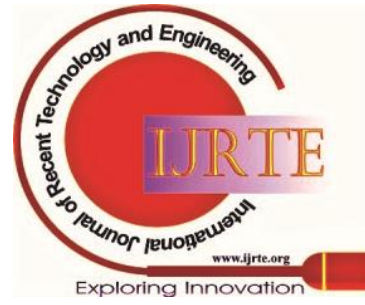


dried in hot air oven at $120^{\circ} \mathrm{C}$ for $24 \mathrm{hr}$. The resulting dried sawdust (RSD) after crushing to particle size of 0.1 to $0.3 \mu \mathrm{m}$ was reserved in a plastic container for further use.

\subsection{Reagents and chemicals}

Technical grade dyes (Methylene Blue and Congo red) and all other reagents used for the experimental studies were bought from Sigma Aldrich Pvt. Ltd and were used as received.

Stock solutions of single and binary dyes $(50 \mathrm{mg} / \mathrm{L})$ were prepared by adding an appropriate quantity in $1 \mathrm{~L}$ deionized water. All working/or standard sample solutions of selected concentrations were further prepared by diluting the stock solution with water.

The real wastewater used in this study was dairy wastewater which was collected from Dairy farm near Graphic Era University, Dehradun city in India. A known amount of both MB and CR dyes was added in the dairy wastewater sample.

\subsection{Equipments used}

The morphological characteristics of adsorbent were examined by using field emission scanning electron microscope (FE-SEM) (Leo Elektronemikroskopie $\mathrm{GmbH}$, Germany). EDX analysis of RSD was made to confirm the elemental composition of RSD before and after loading of dye on its surface.The $\mathrm{pH}$ evaluation of the water sample wasmadeon $\mathrm{pH}$ meter (Model Hach SensION+MM150). The COD (chemical oxygen demand) of real wastewater was assessedonCOD digester by digestion of water samplefor $2 \mathrm{hr}$ at $150^{\circ} \mathrm{C}$ (Aqua Lytic, Checkit Direct COD VARIO). The turbidity of the wastewater was determined by Turbidity meter (Aqua Lytic, PC Compact). A UV-Vis spectrophotometer (UV10HEDM218008) was made to measure the concentration of adsorbate that remain in the sample medium.

\subsection{Batch adsorption studies}

The isotherm and kinetic studies were conducted for simulated wastewater containing single dyes under batch mode method. Various operating conditions were considered in this study namely:temperature,contact time, initial dyes concentration, RSD dosage and $\mathrm{pH}$.

For adsorption isotherm studies, $100 \mathrm{~mL}$ of individual dyes solution of varying concentrations $(0.05-40 \mathrm{mg} / \mathrm{L})$ and a fixed amount of biosorbent (RSD) was mixed in a series of $250 \mathrm{~mL}$ beakers. Similar experiment was carried out for kinetic studies with fixed optimized conditions (adsorbate concentration: $10 \mathrm{mg} / \mathrm{L}$; RSD dosage: $1 \mathrm{~g} / \mathrm{L}$ ) but under varying interval of time $s$ (5-180). During the course of experiments, $\mathrm{pH}$ and temperature of the sample solutions was maintained constant. In all experiments, the beakers containing reaction medium was placed under stirring on orbital shaker at $25^{\circ} \mathrm{C}$ and at $100 \mathrm{rpm}$. The concentrations of dye in the adsorption medium (final) weremeasured on UVVis spectrophotometer at wavelength of $664 \mathrm{~nm}$ for MB and $500 \mathrm{~nm}$ for $\mathrm{CR}$, respectively. The maximum adsorption efficiency (qe, $\mathrm{mg} / \mathrm{g}$ ) was computed by using the equation as addressed below:

$\mathrm{q}_{\mathrm{e}} \quad=\quad\left(\begin{array}{llll}\mathrm{C}_{\mathrm{o}} & - & \mathrm{C}_{\mathrm{e}}\end{array}\right) \quad \mathrm{V} / \mathrm{W}$

(1)

Where

$\mathrm{C}_{\mathrm{o}}=$ initial dye concentration $(\mathrm{mg} / \mathrm{L})$,
$\mathrm{C}_{\mathrm{e}}=$ final concentration of dye $(\mathrm{mg} / \mathrm{L})$,

$\mathrm{V}=$ volume of the liquid sample $(\mathrm{L})$

$\mathrm{W}=$ weight of biosorbent (RSD) $(\mathrm{g})$.

A similar batch adsorption experiments were performed for simulated and real combine dyes wastewater. All batch tests were undertaken in triplicate and the meanresults were documented.

\section{RESULTS AND DISCUSSION}

\subsection{Characterization studies of RSD}

SEM micrograph and EDX spectrum of RSD before and after loading with MB dye are exhibited in Figure 1(a,b). Fe-SEM image of RSD (Fig. 1a) reveals a heterogeneous and rough surface of RSD. Whereas SEM micrograph of RSD loaded with dye (Fig. 1b) exhibits changed surface morphology attributed to the impregnation of dye particles onto RSD. The EDX result announced the carbonaceous surface of RSD as revealed from the high percentage of carbon content $(67.2 \%)$ (Fig.1a). The presence of N, S and $\mathrm{Cl}$ content in Figure $1 \mathrm{~b}$ indicates the interaction of dye molecule with RSD. The weight \% of nitrogen, sulphur and chlorine as determined from EDX is $3.6 \%, 5.3 \%$ and $1.2 \%$ respectively, which further certifies the effective loading of MB dye on RSD surface.

The FTIR spectral analysis of RSD and after loaded with MB dye is represented in Fig. 2. The FTIR spectra of RSD declares the existence of different hydroxyl, carboxylic and phenolic functional moieties as evidenced by various bands at 3223 and $1738 \mathrm{~cm}^{-1}$ (corresponding to $-\mathrm{OH}$ stretch of phenols and carboxylic groups), 1511and $1396 \mathrm{~cm}^{-1}$ (corresponding to $\mathrm{C}=\mathrm{O}$ stretching vibration of carboxylate group), $1469 \mathrm{~cm}^{-1}$ and $1400 \mathrm{~cm}^{-1}$ (corresponding to $\mathrm{C}-\mathrm{O}$ stretching of carboxyl group), $1122 \mathrm{~cm}^{-1}$ (C-OH stretching vibration of alcoholic group). The FTIR spectrum of RSD loaded with $\mathrm{MB}$ and $\mathrm{CR}$ dye reveals the shifting and disappearance of some absorption peak frequencies that are mainly corresponding to carboxylic, phenolic and hydroxyl groups. Significant band shifting from $1511 \mathrm{~cm}^{-1}$ to 1503 and $1515 \mathrm{~cm}^{-1}$ and from $1122 \mathrm{~cm}^{-1}$ to 1109 and $1127 \mathrm{~cm}^{-1}$ after adsorption of $\mathrm{MB}$ and $\mathrm{CR}$ dye, reveal that such functionalities on RSD surface were able to bind dye molecules from wastewater. The disappearance of the two peaks at $1738 \mathrm{~cm}^{-1}$ and $1396 \mathrm{~cm}^{-1}$ (present in RSD) revealed the involvement of $-\mathrm{OH}$ and $\mathrm{C}=\mathrm{O}$ functionalities in the binding of dyes.

\subsection{Characterization analysis of real wastewater}

The characterization analysis of the real wastewater is addressed in Table 1.The $\mathrm{pH}$ of the collected wastewater was 7.29. The wastewater showed a high total solid of $3.13 \mathrm{~g} / \mathrm{L}$ and a high turbidity of 1143 NTU. The wastewater also showed the presence of a high organic substance as determined from COD value of $2.6 \mathrm{~g} / \mathrm{L}$.

\section{3. pH studies}

Solution $\mathrm{pH}$ is considered a significant parameter as it can affect the surface charge of the adsorbent and structural stability of dyes molecules [28].

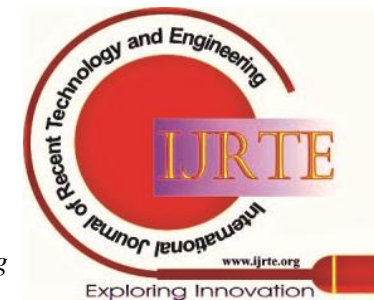


$\mathrm{pH}$ studies can also reflect the mechanisms of the adsorption process and various physico-chemical interactions of adsorbate-adsorbent system [29].

The $\mathrm{pH}$ dependent batch studies were carried out at fixed adsorbent dosage of $1 \mathrm{~g} / \mathrm{L}$, fixed dye concentration of $10 \mathrm{mg} / \mathrm{L}$ and at $25^{\circ} \mathrm{C}$ and outcomes are illustrated in Fig. 3(a,b). Experimental studies showed highest uptake of MB and CR was observed at $\mathrm{pH} 6$ and 2 respectively.In case of MB dye (Fig. 3a), increase uptake of cationic adsorbates at higher $\mathrm{pH}$ conditions $(\mathrm{pH}=6)$ could have resulted due to the strong electrostatic interaction onto the deprotonated RSD. Whereas, in case of CR dye (Fig. 3b), the reduction in the sorption of anionic adsorbate under alkaline $\mathrm{pH}$ could be due to increased repulsion from the negatively charged surface of RSD. Figure 3(a, b) also demonstrates that the final $\mathrm{pH}$ showed slight increase after the sorption of both cationic and anionic adsorbates. It could thus be inferred that the binding mechanism can be electrostatic [30].

\subsection{Effect of contact time}

The effect of varying contact time on sorption efficiency of RSD was carried out at fixed $\mathrm{pH}$, fixed RSD dosage, and fixed adsorbate concentration $(10 \mathrm{mg} / \mathrm{L})$; results are demonstrated in Figure 4. The figure showed that the uptake of both dyes was quite rapid within first 60minand the equilibrium was obtained at $180 \mathrm{~min}$. The uptake capacity $(\mathrm{mg} / \mathrm{g})$ increased from 3.5 to $8.4 \mathrm{mg} / \mathrm{g}$ for $\mathrm{MB}$ and 3.3 to $8.0 \mathrm{mg} / \mathrm{g}$ for $\mathrm{CR}$ respectively, within $60 \mathrm{~min}$ at an adsorbate concentration of $10 \mathrm{mg} / \mathrm{L}$. The reduction in the adsorption rate with longer contact may be attributed to the agglomeration of adsorbate particles; thus resulting in resistance to further diffusion [31]. On the other hand, RSD showed its higher efficiency to adsorb MB dye as compared to that for CR. This may be because of the lower solubility of $\mathrm{MB}$ in water (solubility of $\mathrm{MB}$ in water: $43.6 \mathrm{~g} / \mathrm{L}$; solubility of CR in water: $116 \mathrm{~g} / \mathrm{L}$ ).

\subsection{Adsorption isotherm studies}

Fig. 5(a-c) illustrates the adsorption isotherm results achieved for RSD for the two selected dyes MB and CR at varying adsorbate concentrations (0.05-40 $\mathrm{mg} / \mathrm{L})$. Experiments were carried out under predetermined optimized conditions (constant RSD dosage of $1 \mathrm{~g} / \mathrm{L}$, fixed $\mathrm{pH}$ of 6 for $\mathrm{MB}$ and 2 for $\mathrm{CR}$, at $25^{\circ} \mathrm{C}$ ) and results are depicted in Figure 5 (a-c).

With an aim to investigate the best fitting model for the studied sorption process, the isotherm data were further implemented to the following three isotherm models: Langmuir[32], Freundlich [33] and Dubinin-Redushkevich (D-R) [34].

Langmuir (eq. 2), Freundlich (eq. 3) and D-R (eq. 4) model equations can be stated as follows:

$1 / \mathrm{q}_{\mathrm{e}}=1 / \mathrm{Q}_{\mathrm{o}}+1 / \mathrm{bQ} \mathrm{o}_{\mathrm{o}}(2)$

$\log \mathrm{q}_{\mathrm{e}}=\log \mathrm{K}_{\mathrm{f}}+1 / \mathrm{n} \log \mathrm{C}_{\mathrm{e}}$ (3)

$\log \mathrm{q}_{\mathrm{e}}=\log \mathrm{q}_{\mathrm{D}}-2 \mathrm{~B}_{\mathrm{D}} \mathrm{R}^{2} \mathrm{~T}^{2} \log \left(1+1 / \mathrm{C}_{\mathrm{e}}\right)$

From the aforesaid equations, $b(\mathrm{~L} / \mathrm{g})$ and $\mathrm{Q}_{\mathrm{o}}(\mathrm{mg} / \mathrm{g})$ designate the Langmuir constants corresponding to the energy of sorption and adsorbate uptake potency. $\mathrm{q}_{\mathrm{e}}(\mathrm{mg} / \mathrm{g})$ represents the amount of the dyes adsorbed per gram of RSD and $\mathrm{C}_{\mathrm{e}}(\mathrm{mg} / \mathrm{L})$ denotes the equilibrium concentration of the dyes. $\mathrm{n}$ and $\mathrm{K}_{\mathrm{f}}$ denote the Freundlich constant. $\mathrm{B}_{\mathrm{D}}$ is a $\mathrm{D}$ -
$R$ constant correlated to the sorption energy, andq ${ }_{D}(\mathrm{mg} / \mathrm{g})$ is the theoretical assessed saturation capacity.

The resulting values of all model parameters and also correlation coefficient for all dyes (MB and CR) assessed from the intercept and slope of plot of Langmuir $\left(1 / \mathrm{q}_{\mathrm{e}}\right.$ versus $1 / \mathrm{C}_{\mathrm{e}}$ ); Freundlich $\left(\log \mathrm{q}_{\mathrm{e}}\right.$ vs. $\log \mathrm{C}_{\mathrm{e}}$ ); and DubininRedushkevich $\left[\log \mathrm{q}_{\mathrm{e}}\right.$ vs. $\left.\log \left(1+1 / \mathrm{C}_{\mathrm{e}}\right)\right]$ are addressed in Table no. 2. The outcomesexplain that irrespective of the adsorbate type and adsorbate conditions, Langmuir model could best describe the isotherm data as revealed from high $\mathrm{R}^{2}$ values shown in Table- 2 . While, Freundlich model best explained the experimental data at higher adsorbate concentrations (5-40 mg/L). From such observation, it can be inferred that although dye molecules formed a monolayer on the RSD surface but at very high concentrations, multilayer may also have formed. The monolayer uptake efficacy $\left(\mathrm{Q}_{\mathrm{o}}\right)$ for $\mathrm{MB}$ and $\mathrm{CR}$ was estimated to be 8.93 and $7.30 \mathrm{mg} / \mathrm{g}$ respectively. Similar results were observed by Raman et al. [35] in their study for the removal of sulfated azo and double azo dyes from wastewater using Prosopis Juliflora Pods.

Table-2 further depicts that the valueof $E_{D}$ as determined from D-R model was assessed to be $<8 \mathrm{~kJ} / \mathrm{mol}$; thereby assuming the binding of dyes to be a physical process.

$\mathrm{E}_{\mathrm{D}}=$

(5) $1 / \sqrt{2} \mathrm{~B}_{\mathrm{n}}$

\subsection{Assessment of the performance of RSD under simulated wastewater condition with binary dyes system}

Since the dyes present in wastewaters are eliminated via sorption onto the adsorbent surface and since the active sites are limited, the capacity of the biosorbent may be affected or hindered due to the presence of a combination of dyes in the wastewater.With this hypothesis, batch studies were conducted with RSD on the simulated wastewater prepared in the laboratory containing the two model dyes (CR and $\mathrm{MB})$. The experiments were made under similar optimized conditions (RSD dosage: 1g/L; contact time: 60mins; adsorbate concentration: $10 \mathrm{mg} / \mathrm{L}$; and $\mathrm{pH} 2$ for Congo red and 6 for Methylene blue) as determined in the previous experiments.Results reveal that the $(\%)$ removal of cationic and anionic dye from simulated combined dyes wastewater was $88 \%$ and $84.8 \%$, respectively (Table 3 ). While the same as determined for $\mathrm{MB}$ and $\mathrm{CR}$ from the single dyes wastewater conditions under similar experimental conditions were $89 \%$ and $86 \%$, respectively. Such results are in line with the hypothesis thus proposed. But significant differences were not observed; thereby revealing the better efficiency of RSD for separation of diverse types of dyes from wastewater. Similar outcomes were proposed by Liu et al. [36] in his studies for the adsorption of cationic and anionic dyes from single and binary systems onto montmorillonite-pillared grapheme oxide. As per his observation, he concluded that the increase in the removal efficiency under binary system may be due to the interplay of synergistic effect between both cationic and anionic dyes simultaneously exist in sample solution.

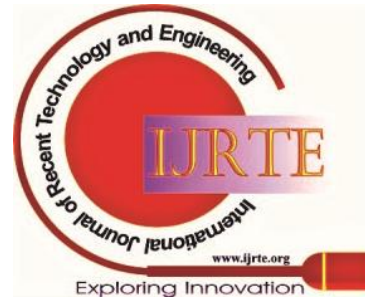




\subsection{Assessment of the performance of RSD under real wastewater with binary dyes system}

Real wastewater was collected from a dairy farm near Graphic Era (deemed to be University), Dehradun; with an aim to assess the performance of RSD as a biosorbent under real wastewater conditions. Characterization analyses carried out revealed high solids content of $3.13 \mathrm{~g} / \mathrm{L}$ (Table1). Presence of high organic matter was evident from a COD value of $2.6 \mathrm{~g} / \mathrm{L}$. $\mathrm{pH}$ of the wastewater was 7.29. Batch experiments were conducted under fixed optimized conditions as determined earlier. The contact time was fixed at 60 mins. While the biosorbent dosage taken was $1 \mathrm{~g} / \mathrm{L}$, the concentration of dyes selected for the study was $10 \mathrm{mg} / \mathrm{L}$. $\mathrm{pH}$ of the wastewater medium was fixed at 6 for $\mathrm{MB}$ and 2 for $\mathrm{CR}$. The outcomes as documented in Table- 3 reveal that the $\%$ adsorption of $\mathrm{CR}$ and $\mathrm{MB}$ dye by RSD was $82 \%$ and $78 \%$ respectively. The decrease in the removal potency of dyes from real wastewater in respect of simulated conditions under identical optimized conditions could be attributed to the presence of organic pollutants which could have hindered the removal efficiency of dyes. The final COD of the real wastewater was also reduced to $1.29 \mathrm{~g} / \mathrm{L}$; thereby indicating the potential of RSD to remove organic matter. Experimental results thus reveal that the RSD has not only the potential to effectively remove dyes to a significant extent but also, a significant amount of the organic pollutants were removed as a result of the treatment process. Isotherm studies conducted at different adsorbate concentrations $(0.05-40 \mathrm{mg} / \mathrm{L})$ under fixed optimized conditions of $\mathrm{pH}$, temperature and contact time in real wastewater conditions reveal similar findings to that obtained under simulated wastewater condition (Table-4). The $\mathrm{Q}_{\mathrm{o}}$ values for $\mathrm{CR}$ and $\mathrm{MB}$ was calculated to be 5.81 and $6.87 \mathrm{mg} / \mathrm{g}$, respectively.

Similar observation was made by Turabik [37] in their studies for the uptake of cationic and anionicdyes on bentonite from both simulated and real wastewater containing single/mixture of dyes. As per his observation, the reduction in adsorption capacity of both dyes in binary system under real wastewater condition in comparison to simulated wastewater containing single dyes may be due to the opposed interaction between the dyes and other organic/inorganic pollutants present simultaneously in real wastewater.

\section{CONCLUSION}

Raw saw dust (RSD) without any modification can serve as an effective biosorbent for sequestration of toxic dyes from aqueous solution. With this assumption, two model dyesCongo red and Methylene Blue with different characteristics were selected for the present study so as to assess the binding mechanism onto RSD. Batch tests carried out on RSD under simulated conditions reveal the sensitivity of the adsorption process over $\mathrm{pH}$ with maximum removal of $\mathrm{CR}$ and $\mathrm{MB}$ dye taking place at $\mathrm{pH}$ of 2 and 6 , respectively. FTIR and $\mathrm{pH}$ studies reveal the binding mechanism to be electrostatic, while kinetic studies reveal a particle or pore diffusion to be operative. At an optimum contact time of $60 \mathrm{mins}$ and under adsorbate concentration of $10 \mathrm{mg} / \mathrm{L}$, the maximum uptake capacity $\left(\mathrm{Q}_{\mathrm{o}}\right)$ of $\mathrm{RSD}$ for $\mathrm{CR}$ and $\mathrm{MB}$ as calculated from the Langmuir model was 7.30 and 8.93 $\mathrm{mg} / \mathrm{g}$, respectively. Irrespective of the nature of the dye, isotherm studies indicate a monolayer formation at lower adsorbate concentrations which Freundlich model could have operated at higher concentrations.

Batch studies were conducted in binary systems in simulated as well as in real waste water and under the pre-determined optimized operating conditions so as to assess the potential of RSD in different aqueous medium. Results as obtained under simulated binary system reveal no significant difference in the performance of RSD and this could be attributed to the fact that there may not be any competitive relationship between the cationic (MB) and anionic (CR) dyes for the surface active sites when present simultaneously in the wastewater. On the other hand, the results as obtained under real wastewater binary system reveal lower removal capacity of RSD for dyes. Competitive adsorption of organic pollutants simultaneously present in the wastewater could have resulted in a net decrease in the efficiency of RSD for uptake of dyes. A reduction of COD to the tune of $50 \%$ in the real wastewater further confirms this observation. The experimental results thus verify the usefulness of RSD as biosorbent for better sequestration of dyes under various wastewater conditions.

\section{REFERENCE}

1. A.A. Giwa, M.A. Oladipo, K.A. Abdulsalam, Adsorption of Rhodamine B from single, binary and ternary dye systems using sawdust of parkiabiglobosa as adsorbent: Isotherm, kinetics and thermodynamics studies, J. Chem. Pharm. Res. 7 (2015) 454-475.

2. A. Kurniawan, H. Sutiono, N. Indraswati, S. Ismadji, Removal of basic dyes in binary system by adsorption using rarasaponinbentonite: Revisited of extended Langmuir model, Chem. Eng. J. 189 (2012) 264- 274.

3. V.K. Gupta, A. Nayak, S. Agarwal, I. Tyagi, Potential of activated carbon from waste rubber tire for the adsorption of phenolics: effect of pre-treatment conditions, J. Colloid Interface Sci. 417 (2014) 420430 .

4. A. Nayak, B. Bhushan, V. Gupta, L. Rodriguez-Turienzo, Development of a green and sustainable clean up system from grape pomace for heavy metal remediation, J. Environ. Chem. Eng. 4 (2016) 4342-4353

5. C.M. Castilla, J.R. Utrilla, Carbon materials as adsorbents for the removal of pollutants from the aqueous phase, Mater. Res. Soc. Bull. 26 (2001) 890-894.

6. M. Ghasemi, M. Naushad, N. Ghasemi, Y. Khosravi-fard, A novel agricultural waste based adsorbent for the removal of $\mathrm{Pb}$ (II) from aqueous solution: kinetic, equilibrium and thermodynamic studies, J. Ind. Eng. Chem. 20 (2014) 454-460.

7. J.J. Salazar-Rabago, R. Leyva-Ramos, J. River-Utrilla, R. OcampoPerez, F.J. Cerino-Cordova, Biosorption mechanism of methylene blue from aqueous solution onto white pine (Pinus durangensis) sawdust: effect of operating conditions, Sustainable Environ. Res. 27 (2017) 32-40.

8. U. Farooq, J.A. Kozinski, M.A. Khan, M. Athar, Biosorption of heavy metal ions using wheat based biosorbents-a review of the recent literature, Bioresour. Technol. 101 (2010) 5043-5053.

9. R.B. Garcia-Reyes, J.R. Rangel-Mendez, Adsorption kinetics of chromium(III) ions on agro-waste materials, Bioresour. Technol. 101 (2010) 8099-8108

10. K.S. Bharathi, S.T. Ramesh, Removal of dyes using agricultural waste as low-cost adsorbents: a review, Appl. Water Sci. 3 (2013) 773-790.

11. M.A. Mohammed, A. Shitu, M.A. Tadda, M. Ngabura, Utilization of various agricultural waste materials in the treatment of industrial wastewater containing heavy metals: a review, Int. Res. J. Environ. Sci. 3 (2014) 62-71.

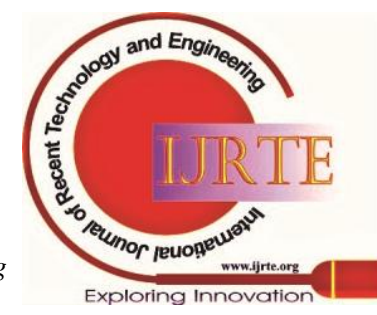


12. F. Ferrero, Dye removal by low cost adsorbents: hazelnut shells in comparison with wood sawdust, J. Hazard. Mater. 142 (2007) 144 152.

13. D. Mohan, H. Kumar, A. Saraswat, M. Alexandre-Franco, C.U Pittman, Cadmium and lead remediation using magnetic oak wood and oak bark fast pyrolysis bio-chars, Chem. Eng. J. 236 (2014) $513-$ 528 .

14. M. Rafatullah, O. Sulaiman, R. Hashim, A. Ahmad, Adsorption of copper (II), chromium (III), nickel (II) and lead (II) ions from aqueous solutions by meranti sawdust, J. Hazard. Mater. 170 (2009) 969-977.

15. V.K. Garg, M. Amita, R. Kumar, R. Gupta, Basic dye (methylene blue) removal from simulated wastewater by adsorption using Indian rosewood sawdust: a timber industry waste, Dyes Pigm. 63 (2004) 243-250.

16. T.A. Khan, S. Sharma, E.A. Khan, A.A. Mukhlif, Removal of congo red and basic violet 1 by chir pine (Pinus roxburghii) sawdust, a saw mill waste: batch and column studies, Toxicol. Environ. Chem. 96 (2014) 555-568.

17. B. Kakoi, J.W. Kaluli, G. Thumbi, A. Gachanja, Performance of activated carbon prepared from sawdust as an adsorbent for endosulfan pesticide, J. Sustainable Res. Eng. 2 (2015) 1-10.

18. R. Ansari, Z. Mosayebzadeh, Removal of basic dye methylene blue from aqueous solutions using sawdust and sawdust coated with polypyrrole, J. Iran. Chem. Soc. 7 (2010) 339-350.

19. G. Cheng, L. Sun, L. Jiao, L.X. Peng, Zhi-hong Lei, Y.X. Wang, J Lin, Adsorption of methylene blue by residue biochar from copyrolysis of dewatered sewage sludge and pine sawdust, Desalin. Water Treat. 51 (2013) 7081-7087.

20. S.D. Khattri, M.K. Singh,Colour removal from synthetic dye wastewater using a bioadsorbent, Water Air Soil Pollut. 120 (2000) 283-294.

21. O. Hamdaoui, Batch study of liquid-phase adsorption of methylene blue using cedar sawdust and crushed brick, J. Hazard. Mater. 135 (2006) 264-273

22. M.M.A. El-Latif, A.M. Ibrahim, M.F. El-Kady, Adsorption equilibrium, kinetics and thermodynamics of methylene blue from aqueous solutions using biopolymer oak sawdust composite, J. Am. Sci. 6 (2010) 267-283

23. B.H. Hameed, A.L. Ahmad, K.N.A. Latiff, Adsorption of basic dye (methylene blue) onto activated carbon prepared from rattan sawdust Dyes Pigm. 75 (2007) 143-149.

24. F.A. Batzias, D.K. Sidiras, Dye adsorption by calcium chloride treated beech sawdust in batch and fixed-bed systems, J. Hazard Mater. 114 (2004) 167-174.

25. B.H. Hameed, A.T.M. Din, A.L. Ahmad, Adsorption of methylene blue onto bamboo-based activated carbon: kinetics and equilibrium studies, J. Hazard. Mater. 141 (2007) 819-825.

26. A. Ahmad, M. Rafatullah, O. Sulaiman, M.H. Ibrahim, R. Hashim, Scavenging behavior of meranti sawdust in the removal of methylene blue from aqueous solution, J. Hazard. Mater. 170 (2009) 357-365.

27. K. Kadirvelu, M. Kavipriya, C. Karthika, M. Radhika, N. Vennilamani, S. Pattabhi, Utilization of various agricultural wastes for activated carbon preparation and application for the removal of dyes and metal ions from aqueous solutions, Bioresour. Technol. 87 (2003) 129-132.

28. V.S. Mane, P.V.V. Babu, Studies on the adsorption of brilliant green dye from aqueous solution onto low-cost $\mathrm{NaOH}$ treated saw dust, Desalin. 273 (2011) 321-329.

29. S. Babel, T.A. Kurniawan, Cr(VI) removal from synthetic wastewate using coconut shell charcoal and commercial activated carbon modified with oxidizing agents and/or chitosan, Chemosphere 54 (2004) 951-967

30. R. Gong, J. Ye, W. Dai, X. Yan, J. Hu, X. Hu, S. Li, H. Huang, Adsorptive removal of methyl orange and methylene blue from aqueous solution with finger citron residue-based activated carbon, Ind. Eng. Chem. Res. 52 (2013) 14297-14303

31. J.E. Aguiar, B.T.C. Bezerra, A.C.A. Siqueira, D. Barrera, K. Sapag, D.C.S. Azevedo, S.M. P. Lucena, I.J. Silva, Improvement in the adsorption of anionic and cationic dyes from aqueous solutions: a comparative study using aluminium pillared clays and activated carbon, Sep. Sci. Technol. 49 (2014) 741-751.

32. I. Langmuir, The adsorption of gases on plane surfaces of glass, mica and platinum, J. Am. Chem. Soc. 40 (1918) 1361-1403.

33. H.M.F. Freundlich, Over the adsorption in solution, J. Phys. Chem. 57 (1906) $385-470$
34. M.M. Dubinin, E.D. Zaverina, L.V. Redushkevich, Sorption and structure of active carbons. I. adsorption of organic vapors, Zh. Fiz. Khim. 21 (1947) 1351-1362.

35. M.K. Raman, G. Muthuraman, Removal of binary mixture of textile dyes on prosopisjuliflora pods - equilibrium, kinetics and thermodynamics studies, Iran. J. Energy Environ. 8 (2017) 48-55.

36. L. Liu, B. Zhang, Y. Zhang, Y. He, L. Huang, S. Tan, X. Cai, Simultaneous removal of cationic and anionic dyes from environmental water using montmorillonite-pillared graphene oxide, J. Chem. Eng. Data 60 (2015) 1270-1278.

37. M. Turabik, Adsorption of basic dyes from single and binary component systems onto bentonite: simultaneous analysis of basic red 46 and basic yellow 28 by first order derivative spectrophotometric analysis method, J. Hazard. Mater. 158 (2008) 52-64

\section{ACKNOWLEDGEMENTS}

The authors are highly grateful to the Graphic Era University, Dehradun for givingall essential research opportunities.

\section{LIST OF FIGURES}

Fig. 1: SEM micrographs and EDX of (a) RSD (b) RSD after impregnation of MB dye

Fig. 2:FTIR spectra of RSD and RSD loaded with Methylene blue and Congo red dye

Fig. 3: Effect of $\mathrm{pH}$ of the solution on the uptake of $\mathrm{MB}$ and CR on RSD

Fig. 4: Effect of contact time for uptake of $\mathrm{MB}$ and $\mathrm{CR}$ on RSD

Fig. 5:(a)Adsorption isotherm of dyes on RSD at initial concentration of $0.05-40 \mathrm{mg} / \mathrm{L}$; (b) Adsorption isotherm of dyes on RSD at lower adsorbate concentrations (0.05-2.5 $\mathrm{mg} / \mathrm{L}$ ); (c)Adsorption isotherm of dyes on RSD at higher adsorbate concentrations $(5-40 \mathrm{mg} / \mathrm{L})$ at $25^{\circ} \mathrm{C}$

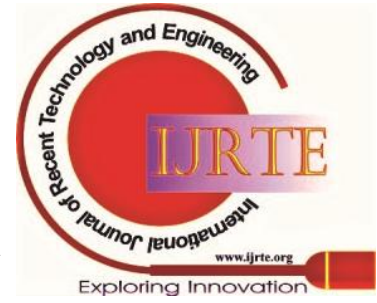


Assessment of Biosorption Potential of Poplar Sawdust for Removal of Dyes from Wastewater under Single and Binary System

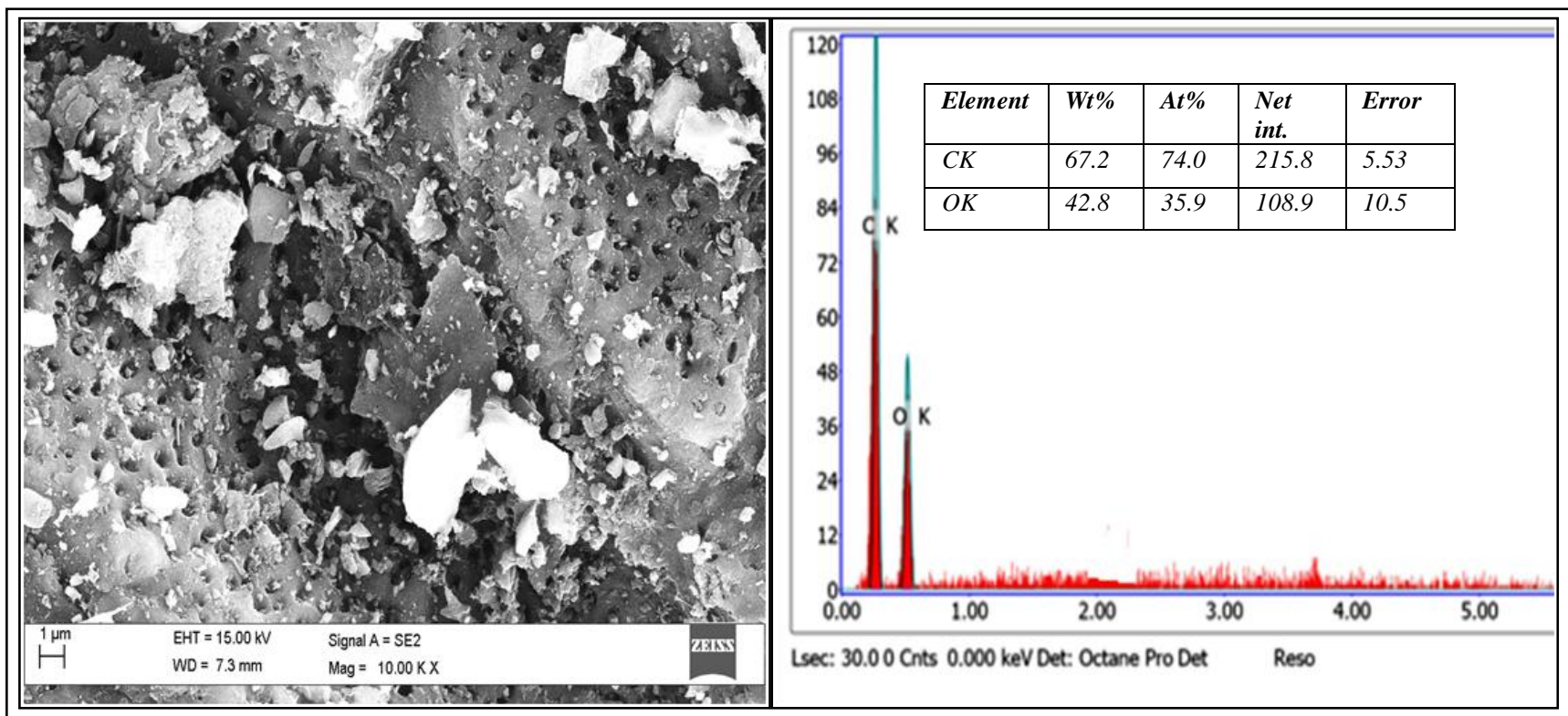

(a)

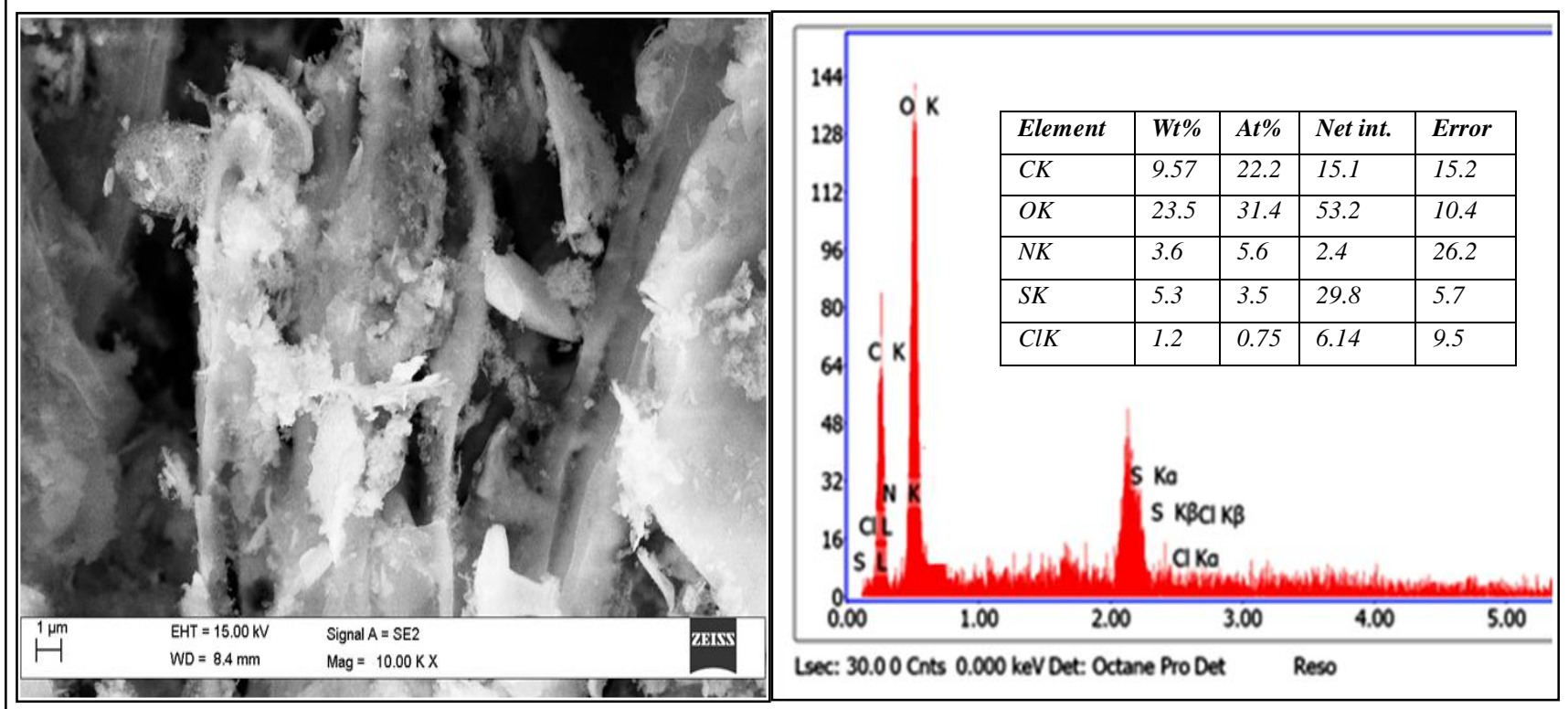

(b)

Fig. 1: SEM micrographs and EDX of (a) RSD (b) RSD after impregnation of MB dye

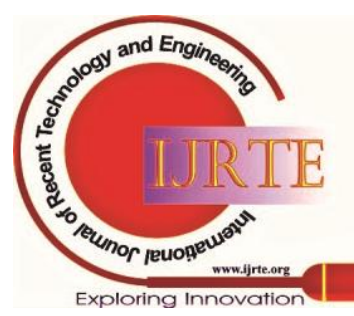




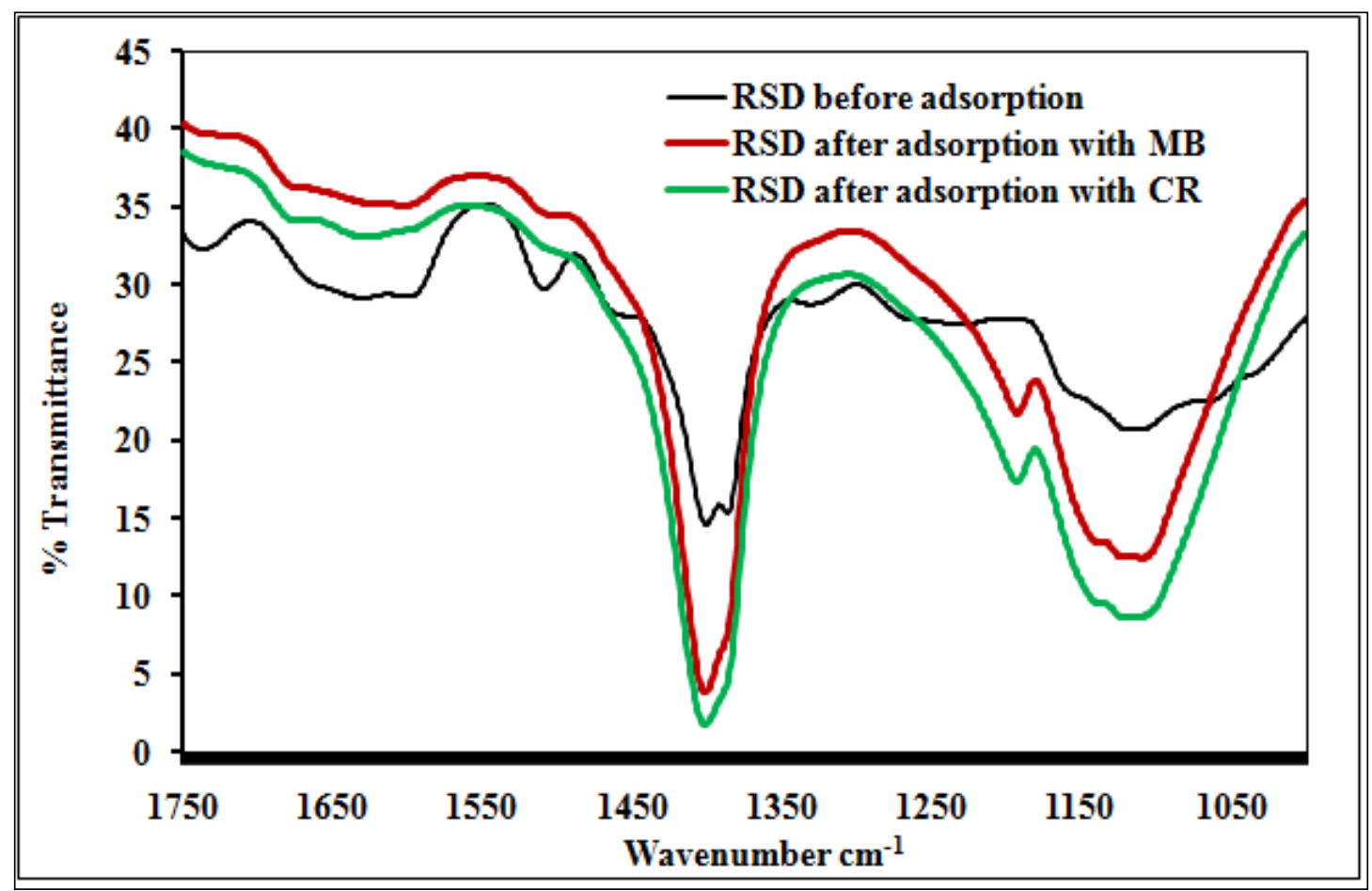

Fig. 2: FTIR spectra of RSD and RSD loaded with Methylene blue and Congo red dye

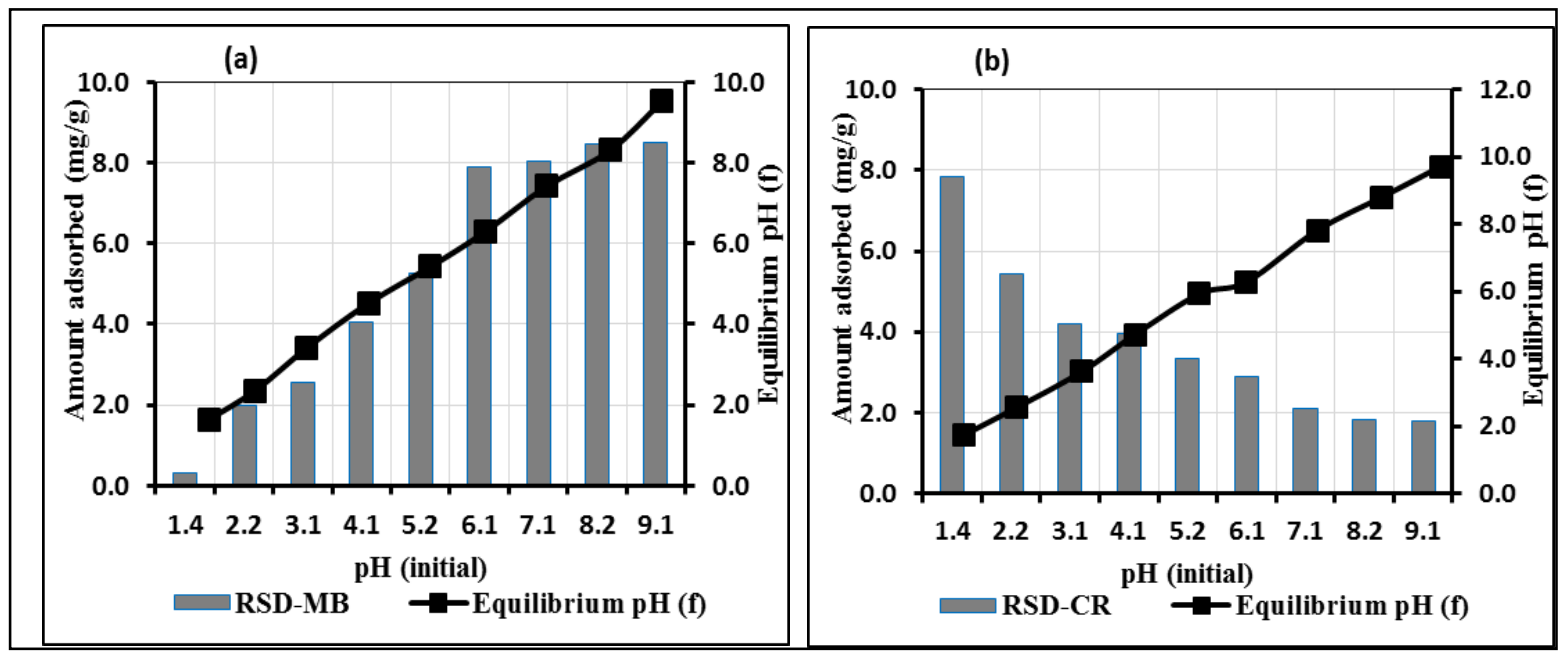

Fig. 3: Effect of pH of the solution on the uptake of (a)MB and (b) CR on RSD

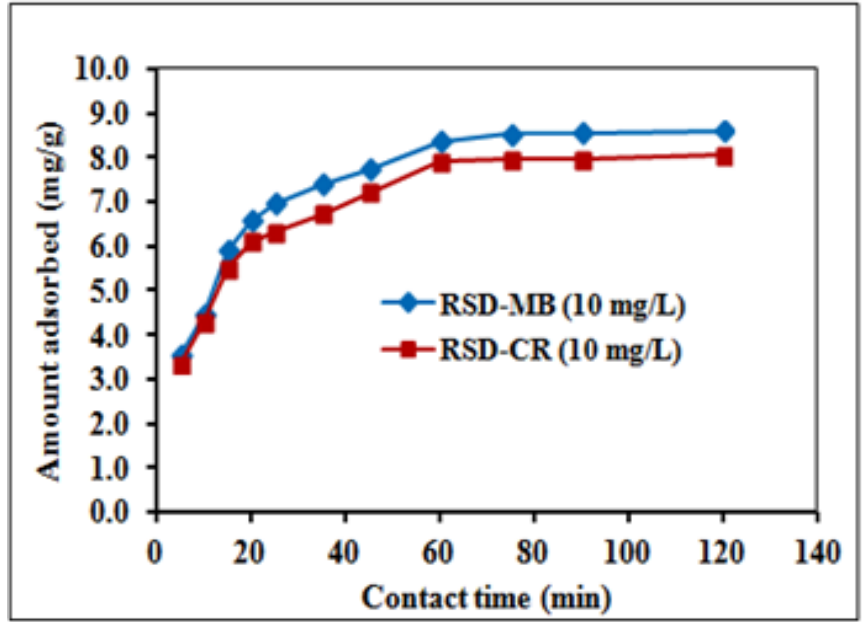

Fig. 4: Effect of contact time for uptake of MB and CR on RSD

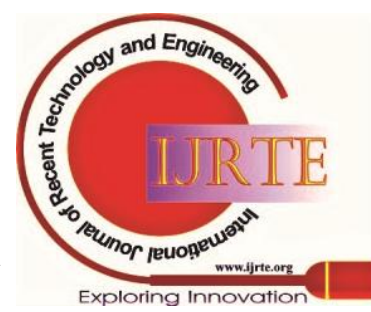




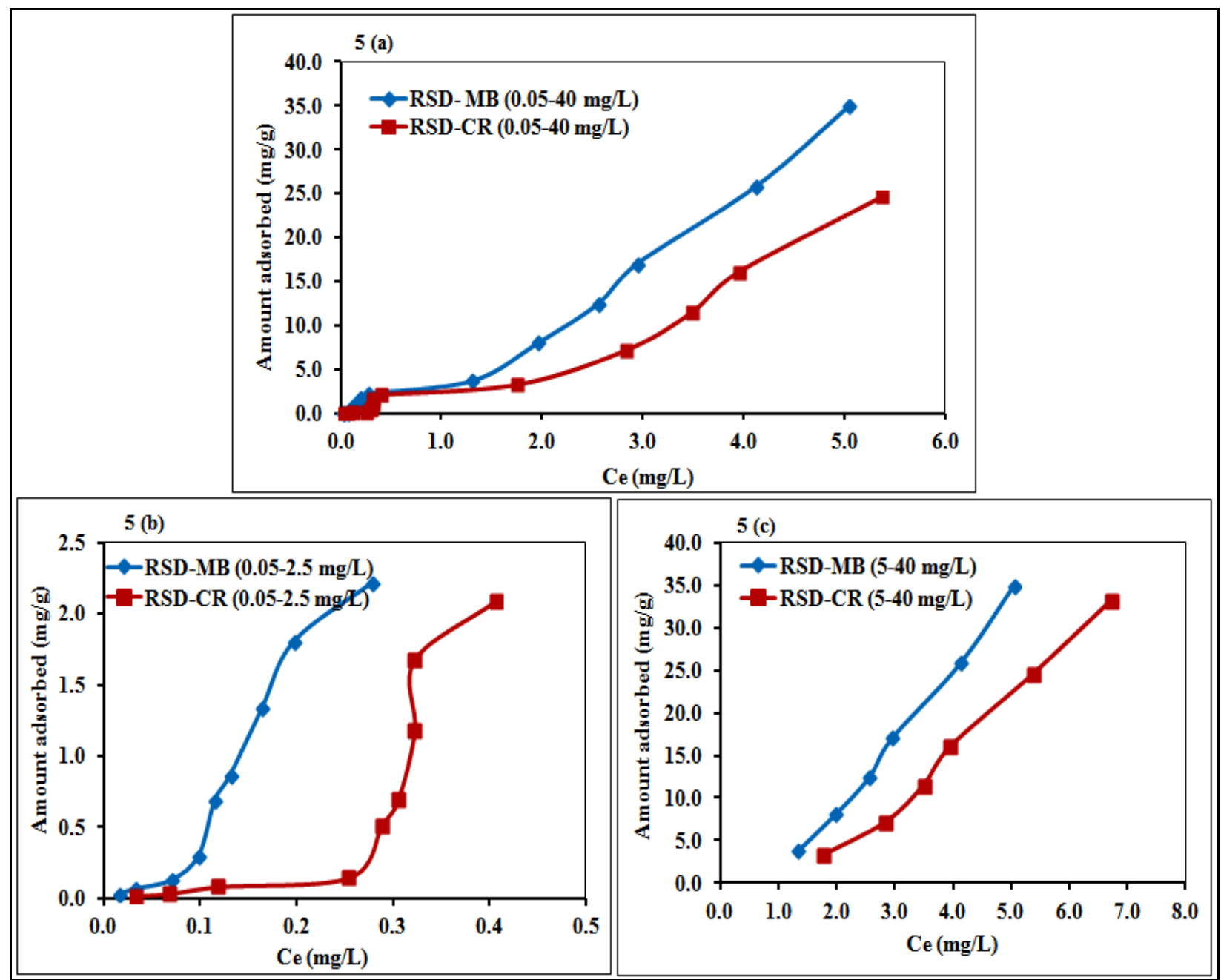

Fig. 5:(a)Adsorption isotherm of dyes on RSD at initial concentration of 0.05-40 mg/L; (b) Adsorption isotherm of dyes on RSD at lower adsorbate concentrations $(0.05-2.5 \mathrm{mg} / \mathrm{L})$; (c)Adsorption isotherm of dyes on RSD at higher

Table legends:

Table 1: Characterization analysis of real wastewater

Table 2:Modelling of isotherm parameters for the uptake of dyes from simulated wastewater containing single dye onto RSD (at $\mathrm{pH} 6$ for $\mathrm{MB}$ and 2 for $\mathrm{CR}$; temperature: $25^{\circ} \mathrm{C}$; contact time: 60 mins)

Table 3: Performance of RSD in simulated and real wastewater containing combined dyes (contact time: 60 mins; RSD dosage: $1 \mathrm{~g} / \mathrm{L} ; \mathrm{pH}$ : 6 for MB and 2 for $\mathrm{CR}$ )

Table 4:Isotherm model parameters for dyes adsorption from simulated and real wastewater containing combined dyes onto RSD (pH 6 for MB and 2 for $\mathrm{CR}$; temperature: $25^{\circ} \mathrm{C}$; contact time: 60 mins)

Table 1: Characterization analysis of real wastewater

\begin{tabular}{|c|c|}
\hline Parameters & Value \\
\hline $\mathrm{pH}$ & 7.29 \\
\hline Turbidity & $1143 \mathrm{NTU}$ \\
\hline COD & $2.6 \mathrm{~g} / \mathrm{L}$ \\
\hline Total Solid (TS) & $3.13 \mathrm{~g} / \mathrm{L}$ \\
\hline Total Dissolved Solid (TDS) & $2.23 \mathrm{~g} / \mathrm{L}$ \\
\hline Total Suspended Solid (TSS) & $1.9 \mathrm{~g} / \mathrm{L}$ \\
\hline
\end{tabular}

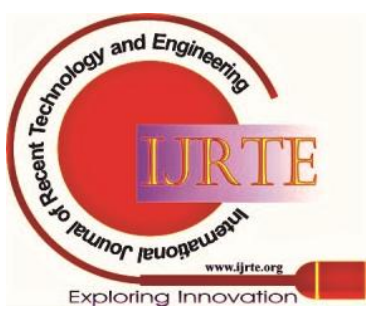


Table 2: Modelling of isotherm parameters for the uptake of dyes from simulated wastewater containing single dye onto RSD (at pH 6 for MB and 2 for $\mathrm{CR}$; temperature: $25^{\circ} \mathrm{C}$; contact time: 60 mins)

\begin{tabular}{|c|c|c|c|c|c|c|}
\hline \multicolumn{7}{|c|}{ Simulated wastewater containing standalone dyes } \\
\hline Biosorbent & \multicolumn{6}{|c|}{ RSD } \\
\hline \multirow[t]{2}{*}{$\begin{array}{c}\text { Adsorbate } \\
\text { concentration }\end{array}$} & \multicolumn{2}{|c|}{$\begin{array}{l}\text { Overall Initial concentration } \\
\qquad(0.05-40 \mathrm{mg} / \mathrm{L})\end{array}$} & \multicolumn{2}{|c|}{$\begin{array}{l}\text { Lower concentration } \\
\qquad(0.05-2.5 \mathrm{mg} / \mathrm{L})\end{array}$} & \multicolumn{2}{|c|}{$\begin{array}{l}\text { Higher concentration } \\
\qquad(5-40 \mathrm{mg} / \mathrm{L})\end{array}$} \\
\hline & MB & $\mathrm{CR}$ & $\mathrm{MB}$ & $\mathrm{CR}$ & $\mathrm{MB}$ & $\mathrm{CR}$ \\
\hline \multicolumn{7}{|c|}{ Langmuir } \\
\hline $\mathrm{Q}_{\mathrm{o}}(\mathrm{mg} / \mathrm{g})$ & 8.93 & 7.3 & 0.33 & 0.1 & 23.8 & 19.6 \\
\hline $\mathrm{b}(\mathrm{L} / \mathrm{mg})$ & 0.224 & 0.06 & 5.57 & 2.24 & 0.15 & 0.13 \\
\hline $\mathrm{R}^{2}$ & 0.98 & 0.98 & 0.99 & 0.99 & 0.98 & 0.98 \\
\hline \multicolumn{7}{|c|}{ Freundlich } \\
\hline $\mathrm{K}_{\mathrm{f}}$ & 6.23 & 4.03 & 32.14 & 26.3 & 42 & 27.5 \\
\hline $\mathrm{n}$ & 1.22 & 1.04 & 0.58 & 0.4 & 2.76 & 2.18 \\
\hline $\mathrm{R}^{2}$ & 0.96 & 0.92 & 0.96 & 0.92 & 0.99 & 0.99 \\
\hline \multicolumn{7}{|c|}{ Dubinin-Redushkevich } \\
\hline $\mathrm{q}_{\mathrm{D}}(\mathrm{mg} / \mathrm{g})$ & 28.8 & 25.1 & 68.2 & 49.3 & 70.3 & 68.5 \\
\hline $\mathrm{E}_{\mathrm{D}}$ & 1.93 & 1.68 & 1.81 & 1.5 & 1.19 & 1.09 \\
\hline $\mathrm{R}^{2}$ & 0.97 & 0.93 & 0.96 & 0.91 & 0.99 & 0.98 \\
\hline
\end{tabular}

Table 3: Performance of RSD in simulated and real wastewater containing combined dyes (contact time: 60mins; RSD dosage: $1 \mathrm{~g} / \mathrm{L}$; $\mathrm{pH}$ : 6 for $\mathrm{MB}$ and 2 for $\mathrm{CR}$; temperature: $25^{\circ} \mathrm{C}$ )

\begin{tabular}{|c|c|c|c|c|c|c|}
\hline \multicolumn{7}{|c|}{ Simulated wastewater with combined dyes } \\
\hline & $\mathrm{pH}(\mathrm{initial})$ & $\mathrm{C}_{\mathrm{o}}(\mathrm{mg} / \mathrm{L})$ & $\lambda(\mathrm{nm})$ & $\mathrm{pH}($ final) & $\mathrm{qt}(\mathrm{mg} / \mathrm{g})$ & $\%$ Removal \\
\hline $\mathrm{MB}$ & 6.07 & 10 & 664 & 6.81 & 8.8 & 88 \\
\hline $\mathrm{CR}$ & 2.18 & 10 & 500 & 2.21 & 8.4 & 84 \\
\hline \multicolumn{7}{|c|}{ Real wastewater with combined dyes } \\
\hline $\mathrm{MB}$ & 6.21 & 10 & 664 & 7.42 & 8.2 & 82 \\
\hline $\mathrm{CR}$ & 2.18 & 10 & 500 & 2.20 & 7.9 & 78 \\
\hline
\end{tabular}

Table 4: Isotherm model parameters for dyes adsorption from simulated and real wastewater containing combined dyes onto RSD (pH 6 for MB and 2 for $\mathrm{CR}$; temperature: $25^{\circ} \mathrm{C}$; contact time: 60 mins)

\begin{tabular}{|c|c|c|c|c|c|c|}
\hline \multicolumn{7}{|c|}{ Simulated wastewater with combined dyes } \\
\hline Biosorbent & \multicolumn{6}{|c|}{ RSD } \\
\hline \multirow{2}{*}{$\begin{array}{c}\text { Adsorbate } \\
\text { concentration }\end{array}$} & \multicolumn{2}{|c|}{$\begin{array}{c}\text { Overall Initial concentration } \\
(0.05-40 \mathrm{mg} / \mathrm{L})\end{array}$} & \multicolumn{2}{|c|}{$\begin{array}{c}\text { Lower concentration } \\
0.05-2.5 \mathrm{mg} / \mathrm{L})\end{array}$} & \multicolumn{2}{|c|}{$\begin{array}{c}\text { Higher concentration } \\
(5-40 \mathrm{mg} / \mathrm{L})\end{array}$} \\
\hline & $\mathrm{MB}$ & $\mathrm{CR}$ & $\mathrm{MB}$ & CR & $\mathrm{MB}$ & $\mathrm{CR}$ \\
\hline \multicolumn{7}{|c|}{ Langmuir } \\
\hline $\mathrm{Q}_{\mathrm{o}}(\mathrm{mg} / \mathrm{g})$ & 8.26 & 7.19 & 0.38 & 0.26 & 23.8 & 19.6 \\
\hline $\mathrm{b}(\mathrm{L} / \mathrm{mg})$ & 0.244 & 0.115 & 4.97 & 1.63 & 0.15 & \\
\hline $\mathrm{R}^{2}$ & 0.98 & 0.96 & 0.99 & 0.99 & & \\
\hline
\end{tabular}


Assessment of Biosorption Potential of Poplar Sawdust for Removal of Dyes from Wastewater under Single and Binary System

\begin{tabular}{|c|c|c|c|c|c|c|}
\hline \multicolumn{7}{|c|}{ Freundlich } \\
\hline $\mathrm{k}_{\mathrm{f}}$ & 6.23 & 4.03 & 19.8 & 7.40 & 38.6 & 33.3 \\
\hline $\mathrm{n}$ & 1.22 & 1.04 & 1.57 & 1.05 & 2.26 & 1.96 \\
\hline $\mathrm{R}^{2}$ & 0.96 & 0.92 & 0.95 & 0.88 & 0.99 & 0.99 \\
\hline \multicolumn{7}{|c|}{ Real wastewater with combined dyes } \\
\hline \multicolumn{7}{|c|}{ Langmuir } \\
\hline $\mathrm{Q}_{\mathrm{o}}(\mathrm{mg} / \mathrm{g})$ & 6.87 & 5.81 & 0.31 & 0.10 & 19.4 & 17.4 \\
\hline $\mathrm{b}(\mathrm{L} / \mathrm{mg})$ & 0.257 & 0.078 & 3.71 & 1.46 & 0.164 & 0.146 \\
\hline $\mathrm{R}^{2}$ & 0.98 & 0.98 & 0.99 & 0.99 & 0.96 & 0.98 \\
\hline \multicolumn{7}{|c|}{ Freundlich } \\
\hline $\mathrm{K}_{\mathrm{f}}$ & 5.82 & 4.03 & 19.8 & 12.0 & 3.86 & 2.75 \\
\hline $\mathrm{n}$ & 0.85 & 0.75 & 0.61 & 0.40 & 2.26 & 2.18 \\
\hline $\mathrm{R}^{2}$ & 0.96 & 0.90 & 0.95 & 0.92 & 0.99 & 0.99 \\
\hline
\end{tabular}

